\title{
DESIGN AND FABRICATION OF PIPE BENDING MACHINE USING HYDRAULIC SYSTEM
}

\author{
R. SATHISH ${ }^{1}$, K. ARAVINTH ${ }^{2}$, R. ASHWIN CHAKRAVARTHY ${ }^{3}$ \& D. JAGATHEESWARAN ${ }^{4}$ \\ ${ }^{I}$ Assistant Professor, Department of Mechanical Engineering, Karpagam College of Engineering, Coimbatore - 641032 \\ ${ }^{2}$ Assistant Professor, Department of Automobile Engineering, Karpagam College of Engineering, Coimbatore - 641032 \\ ${ }^{3}$ Assistant Professor, Department of Mechanical Engineering, EGS Pillai Engineering College, Nagapattinam - 611002 \\ ${ }^{4} U G$ Scholar, Department of Automobile Engineering, Karpagam College of Engineering, Coimbatore - 641032
}

ABSTRACT
In industry, bending machine with hydraulic system is most commonly used for bending the pipe to the required shape.
This system consists of a hydraulic cylinder, ram, die holder. It was operated by hand. Pressurized oil supplied to cylinder
using ram (hydraulic). Piston and connecting rod is situated in cylinder. Ram was placed at the top of the cylinder. To
increase the pressure, pressurized oil used which moves the cylinder piston forward. At the die holder pipe is fixed. To
move the piston, ram strikes the pipe with some forces.
KEYWORDS: Die, Roller, Bearing, Frame

Received: Jun 07, 2020; Accepted: Jun 27, 2020; Published: Jul 17, 2020; Paper Id.: IJMPERDJUN2020366

\section{INTRODUCTION}

One of the most versatile devices on the market, the hydraulic bending press helps the users to process different parts by bending, pressing etc. Metal fabricator most commonly uses this hydraulic system to process their needs. It is suitable for small to medium sized industries. Operating procedure of this system is simple compared to other pipe bending machine or system. Further improvement done is placing the jack near the holder, which holds the die. This system increases the bending accuracy and it shows less deflection. Die is carried or moved in required position with the help of die holder. The Die is changed based on the required shape of pipe like $\mathrm{V}$ shape or $\mathrm{L}$ shape.

Functions of Bending Machine

- $\quad$ To give U-shape, 'V' type, 'L' type circular bend of Hollow Pipe.

- The machine needs less maintenance

- The hydraulic powered jack limit from 2.5 ton to 4 ton.

\section{DESIGN PARAMETER}

\section{Design}

It consists of several parts namely:- 


\section{Frame Stand}

For the frame the square pipes of mild steel material are selected.The pipes are cut into required size by cutting machine. These are two identical plates between which the tube is supported to rest. It should be steady and stable so as not to move during the bending phase, which would cause any of the defects mentioned above. The frame provides support for whole parts of the system.

\section{Jack with Hydraulic System}

To lift the heavy loads a jack with hydraulic system as shown in Figure 1. Uses the required amount of forces. Forces created by air are used by the jack to lift the loads placed in the cylinder chamber. This type of jack can withstand upto 4 tonnes.

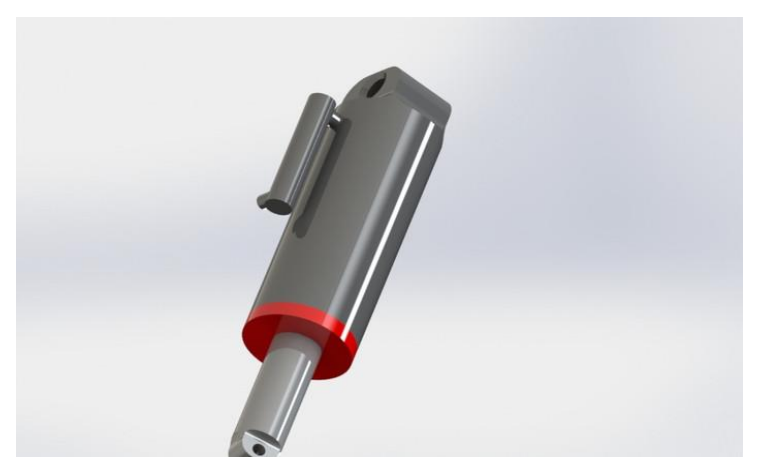

Figure 1: Hydraulic Jack.

\section{Die or Pulley}

A bending die is a screw that is welded to it, and used to secure a pipe securely. In this project two types of dies are used named revolving die and moving die. The die shape is varied depends upon the required shape of the pipe as shown in Figure 2. Such pipe bending shapes are "V"-type, "L"-type, etc.

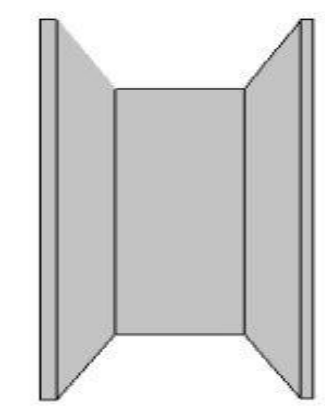

Figure 2: Die or Pulley.

Vice

Vice is a mechanical device used to protect an item, so that work can be done on it. Vises have two parallel jaws, one fixed and the other movable, with a screw and a lever threaded in and out. 


\section{SPECIFICATION}

Table 1: Specification

\begin{tabular}{|c|l|c|}
\hline S.NO & COMPONENTS & SPECIFICATION \\
\hline 1 & Frame & $770 \mathrm{~mm} * 140 \mathrm{~mm}$ \\
\hline 2 & Motor & Power $=0.5 \mathrm{hp}$ and speed $=40 \mathrm{rpm}$ \\
\hline 3 & Stand & $800 \mathrm{~mm} * 200 \mathrm{~mm}$ \\
\hline 4 & Die & Radius $=32.5 \mathrm{~mm}$ and thickness $=45 \mathrm{~mm}$ \\
\hline
\end{tabular}

\section{List of Components}

- Hydraulic jack

- $\quad$ Revolving die

- Moving die

- $\quad$ Pipe-Work piece

- Handle

- $\quad$ Spring

- Frame Stand

- Jack Screw Rod

- Hydraulic Jack piston

\section{WORKING PRINCIPLE}

The 3-roll bending method is used to bend the work piece or pipe to the required radius of bending. It is like ram bending process, with less different about the moving pulley and the two-stationary counter-pulley rotation, creating there are moving pulley and two fixed pulley, with the help of pulley the work piece moves forward and backward also it moves the operating pulley closer to counter pulley, therefore the bending radius gets increased. Due to this bending method there only occurs a little deformation in pipe cross section, It is also suited for producing pipe coils also used for producing sweeping coils.

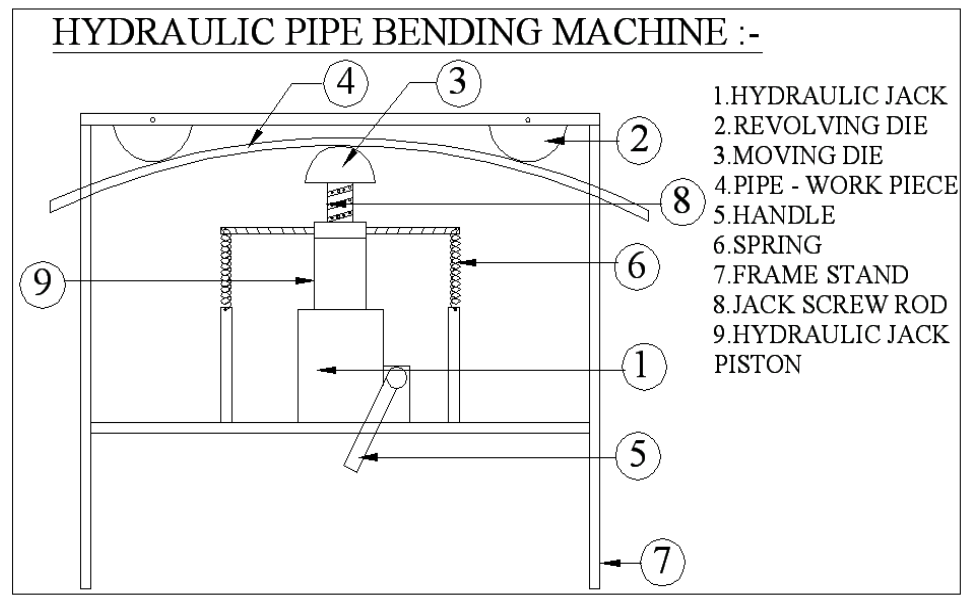

Figure 3: Hydraulic Pipe Bending Machine. 


\section{CONCLUSIONS}

Pipe bending also takes part in making component in automobile, aerospace and power plant industries etc. This pipe bending machine system is completely automated and it is based on microcontroller system, it is less expensive and light in weight. The use of this system can be enhanced in small industries, small workshop holder and also can be used in colleges or institutes for laboratory purpose.

\section{REFERENCES}

1. B.Bhandari (2012) "Design of Machine Elements" Mc Graw Hill.

2. Dhaval Sutar (2015) "International journal of research in mechanical engineering and technology"

3. Jun ZhanoGaocgaoyu Rai Ma "Journal of fabric Processing Technology"

4. Chudasama (2014) Bending Force prediction for dynamic during 3-roller conical bending process. Journal of manufacturing process.

5. S Sumesh \& A R Veerappn "Engineering Failure Analysis"

6. Akbar Khan \& Pravin Ghule is published "Design Development and Experimental Study of Pipe Bending Machine"

7. S.VikashPatial et al., Design And Manufacturing Of Pneumatic Pipe Bending Machine. International Journal of research.

8. Rishipal, Swarna Torgal, M P Kamath, and A S Joshi. "Simple Technique for Fabrication of Toroidal Surface with a Bender and Cylindrical Polishing Machine." International Journal of Mechanical Engineering (IJME) 6.4 (2017):15-26

9. Ahmed, Tabreez, Mohammed Faheem, and M. A. Murtaza. "Case study \& stress analysis of a 3 roller bar bending machine." International Journal of Mechanical and Production Engineering Research and Development (IJMPERD) 3.3 (2013):57-68.

10. Rao, BVS, et al. "Experimental Investigation of Spring Back and Wrinkling Phenomena in Square Pipes during Bending." International Journal of Mechanical and Production Engineering Research and Development (IJMPERD) 9.5 (2019):539-550

11. Dubey, Harrsh K., Satish P. Lokhande, and Rajat G. Kawalkar. "An Analytical Study of Contact Stress and Contact Zone Analysis of Cylindrical (Roller) \& Spherical (Ball) Bearings in Epicycloid Condition." International Journal of Mechanical and Production Engineering Research and Development (IJMPERD) 8.6 (2018):865-872 